Ronny Hauck

\title{
Nießbrauch an Rechten
}

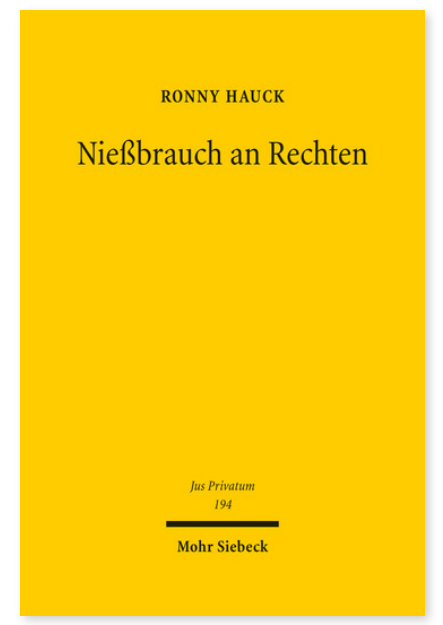

2015. XXVI, 432 Seiten. JusPriv 194

ISBN 978-3-16-154064-6

DOI 10.1628/978-3-16-154064-6

eBook PDF 129,00€

ISBN 978-3-16-153809-4

Leinen $129,00 €$
Rechte - wie etwa Forderungen, Aktien und Patente - können mit anderen Rechten belastet werden. Schon vor Inkrafttreten des BGB war freilich heftig umstritten, wie das Phänomen der »Rechte an Rechten« dogmatisch zu erklären ist. Ronny Hauck geht dieser Frage anhand des Nießbrauchs nach, ausgehend von römisch-rechtlichen Vorbildern über die

Entstehungsgeschichte des BGB bis hin zu aktuellen Entwicklungen auch in Spezialmaterien wie dem Urheberrecht. Gerade anhand der für Immaterialgüterrechte geltenden Grundsätze weist der Autor nach, dass das auf einem engen Sachbegriff basierende Konzept des BGB zur Belastung von Gegenständen dogmatisch nicht schlüssig ist. Notwendig ist vielmehr ein grundlegender Verständniswechsel, der im Ergebnis zu einer abweichenden Vorstellung nicht nur vom Wesen der Belastung führt, sondern vom Regelungsinhalt des BGB-Sachenrechts selbst.

Ronny Hauck Geboren 1972; Studium der Rechtswissenschaft in Erlangen; 2004 Erstes Juristisches Staatsexamen; 2007 Zweites Juristisches Staatsexamen; 2008 Promotion; 2014 Habilitation an der Universität Augsburg; 2014/2015 Lehrstuhlvertretungen an der Universität München sowie am Karlsruher Institut für Technologie.

\section{Jetzt bestellen:}

https://mohrsiebeck.com/buch/niessbrauch-an-rechten-9783161540646?no_cache=1 order@mohrsiebeck.com

Telefon: +49 (0)7071-923-17

Telefax: $+49(0) 7071-51104$ 